\title{
Community Health Systems as Complex Adaptive Systems: Ontology and Praxis Lessons from an Urban Health Experience with Demonstrated Sustainability
}

\author{
Eric Sarriot • Michelle Kouletio
}

Published online: 1 August 2014

(C) The Author(s) 2014. This article is published with open access at Springerlink.com

\begin{abstract}
The global health and development field, which has been reasonably dominated by linear models of planning, is witnessing increased interest in complexity, non-linear processes, and systems thinking. This welcome interest is challenged by both language and ability to discern whether complex development phenomena are discussed from the perspective of the nature of particular health systems (ontology), from the identification of more fitting intervention modalities (praxis), or from our approach to learning and evidence (epistemology). This paper is an experience-based contribution to the first two perspectives. Two Bangladeshi municipal health systems provide an example of how sustainable outcomes were achieved through complex adaptive system behaviors, during and after intervention by Concern Worldwide, Inc. (Concern). Concern provided support to the Municipal Health Departments and then assessed the sustainability of health achievements several years after its intervention. We examine complexity in municipal health systems behavior, and the nonlinearity of project effects. We identify ways in which Concern's program, beyond technical design, followed recommendations on leading complex systems towards positive sustainable outcomes. We conclude on the necessity for global community health planners and practitioners to (1) better understand the complexity of the context and issues they are facing, (2) make more reasonable assumptions about the "shock to the system" caused by projects both when they start and when they end, and (3) learn to balance strategic designs with respect for self-organization principles.
\end{abstract}

Keywords Complex adaptive systems · Community health $\cdot$ Sustainability Complexity · Health systems strengthening

\footnotetext{
E. Sarriot $(\bowtie)$

Center for Design and Research in Sustainable Health and Human Development (CEDARS), ICF International, 530 Gaither Road Suite 500, Rockville, MD 20850, USA e-mail: EricSarriot@gmail.com; Eric.Sarriot@icfi.com

URL: http://www.CedarsCenter.com
}

M. Kouletio

Health Consultant. US Embassy, Formerly with Concern Worldwide Inc, Cotonou, Benin 


\section{Background}

Much development and humanitarian thinking and practice is still trapped in a paradigm of predictable, linear causality and maintained by mindsets that seek accountability through top-down command and control. Recent years have seen more emphasis on the mechanistic approaches of this paradigm and the kinds of procedures which are increasingly questioned by successful private sector organizations. This has widened the gap between actual aid practices and the rhetoric of the many initiatives which aim to improve them-including aid effectiveness, institutional reform, participation, local ownership and empowerment.

In the meantime and in parallel, complexity science has explored and articulated a contrasting world of understanding, helping to explain complex dynamic phenomena in a widely diverse range of settings using insights and concepts like non-linearity, edge of chaos, self-organization, emergence and coevolution.

Robert Chambers (Ramalingam et al. 2008).

The field of global health, as development in general, has been dominated by a traditional and linear input-output-outcomes logic, manifested through strategic plans, results framework and logic models of different types.(Easterly 2006) We are however witnessing a growing interest in complex, non-linear models of intervention and study. This interest is born from (1) the realization that health and development programs are confronted with complex and disorderly patterns (Paina and Peters 2011; Gasparatos et al. 2007; Sarriot et al. 2004), (2) repeated failures in attempting to sustain achievements due to vexing problems (Hafner and Shiffman 2013; Lafond 1995), and (3) increasing attempts of global health interventions to not only deliver discrete results but also strengthen entire systems of care, build capacity, as well as achieve ownership and sustainability (Baser and Morgan 2008; Brinkerhoff and Morgan 2010; de Savigny and Adam 2009; Gruen Gruen 2008; Paina and Peters 2011; Ubels et al. 2010).

As suggested by the quote from Robert Chambers above, global health is facing the same challenges as development as an entire enterprise, perhaps just one generation after the science of sustainable development started to emerge (Meadows 1998; Bossel 1999). Rihani and Geyer (Geyer and Rihani 2010; Rihani 2002a, 2002b) have made substantial contributions to complexity theory as applied to public policy and international development. Rihani argues that ignoring complexity has led to serious failures of development assistance policies and programs by limiting local adaptive capacity. More recently, an interesting body of work has been produced on the nature of capacity and the practice of capacity building in development work. Based on case studies and conceptual reframing, it articulates how complexity and adaptation play a central part in capacity building (Baser and Morgan 2008; Brinkerhoff \& Morgan 2010; Ubels et al. 2010). In the health sector, the World Health Organization (WHO) attempts to address "systems thinking" in two publications (de Savigny and Adam 2009; Janovsky and Peters 2006), with a focus on defining the sub-systems (the 'building blocks') within a health system. (Paina and Peters 2011) offer an articulate review of complex adaptive phenomena, which affect efforts to scale up health system interventions. The authors emphasize path dependence, feedback mechanisms, scale free networks, emergence and phase transition as central features of complex adaptive systems (CAS) to consider. They conclude:

The old assumptions have led to disappointed expectations about how to scale up health services, and offer little insight on how to scale up effective interventions in 
the future. The alternative perspectives offered by CAS may better reflect the complex and changing nature of health systems, and create new opportunities for understanding and scaling up health services.

This interest in systemic practice is still however nascent and is challenged by the requirement for planners and evaluators to adopt new ways of looking at familiar problems and trying to address them.(Ramalingam 2013) The fields of global health practice and research have so far not adapted the inventory of tool—such as the viable systems model of Stafford Beer, Checkland's soft systems methodology, among others-more familiar to organizational systemic practitioners, even though global health takes place within complex networks of organizations and communities. New efforts (Ramalingam et al. 2008; Williams and Hummelbrunner 2010) (Paina and Peters 2011), (Swanson et al. 2012) come with sometimes new language, which challenges the simple language of 'Grand Strategies’. (Hodgins 2014) Appendix 1 (Clarifying our Language: Systems or Complexity or Both?) provides elements of conceptual clarification on the language of complex adaptive systems for readers more familiar with public health practice than systemic approaches.

This paper is an experience-based contribution to the theoretical discussion about health systems as CASs. Two municipal health systems in Saidpur and Paratipur, Bangladesh, and the nongovernment organization, Concern Worldwide, Inc. (Concern), serve as an example of a complex adaptive health system's behavior during and after a partnership and capacity-building intervention that resulted in demonstrated sustainable outcomes on population health indicators. We start with a clarification about our perspective and a word of context about the example which we will build upon.

\section{Perspective Clarification}

Figure 1 suggests three perspectives in current discourse about complexity in global development. Our individual and collective minds naturally tend to jump from trying to understand the nature of the phenomena that interest us and the systems that harbor those phenomena (ontology), to trying to get better at resolving social development problems, (praxis, or how we develop practice from this understanding), and finally to more appropriately studying the phenomena themselves and evaluating the results of our efforts (epistemology). Confusion about systems thinking increases when authors and discussants fail to clarify this perspective (the nature of phenomenon, an intervention, or how to study both).

Paina and Peters (2011) for example provides important ontological parameters in understanding health systems; (Peters et al. 2012; Swanson et al. 2012) uses ontological descriptions to develop interventions on health markets; Rihani stresses the nature of development processes in Southern Countries to recommend new ways of intervening for Northern partners. The work of Chambers has largely focused on development practice, based on implied understandings of the complexity of local systems. Some work in recent years has dealt with epistemology, and notably the type and nature of evidence required for understanding change in a complex adaptive system (Williams and Imam 2007).

We draw illustrations from a project of Concern Worldwide, Inc. (Concern) with two municipal health systems in Bangladesh-specifically through the two Municipal Health Departments (MHDs). We focus on understanding the health systems as complex adaptive systems and draw lessons from the experience of the project with the two municipal systems. 


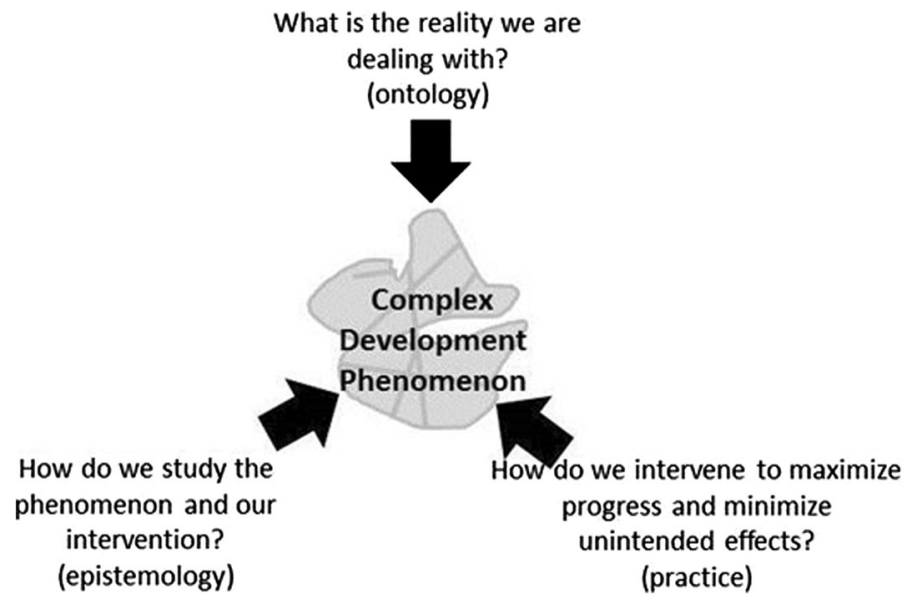

Fig. 1 Three different perspectives of complexity in global development

\section{Context}

Starting in 1998, Concern implemented a United States Agency for International Development (USAID)-funded Child Survival Project in the municipalities of Saidpur and Parbatipur. Concern selected a capacity building approach based on a partnership with the two Municipal Health Departments (MHDs), eschewing direct implementation of activities. Concern adapted the Sustainability Framework method, an approach which includes participatory mapping of the municipal health system; joint definition of a sustainability vision; description of the roles of different governmental and non-governmental actors for achieving this vision; and the definition of the type of capabilities required to ultimately achieve sustainable health outcomes. The method and early implementation by Concern are described elsewhere (Sarriot et al. 2009; Sarriot et al. 2004). Five years after the end of the project, Concern carried out a post-project evaluation with the two municipalities, based on the sustainability framework and indicators agreed upon by stakeholders in the design phase. Twelve indicators of maternal and child health improved tremendously ${ }^{1}$ during the project (1999-2004) (Sarriot 2014). Figure 2a and b show the comparative evolution of two illustrative indicators during and after the project against the national benchmarks of the Bangladesh Demographic and Health Survey (BDHS) urban estimates. It is worth noting that the secular trend had plateaued and was actually on a slow downslide for some indicators (Fig. 2a, in a period of natural and political instability in Bangladesh. In Saidpur and Parbatipur, ten out of the 12 indicators continued to improve or were maintained up to 5 years post-project, even if a plateau at or above national urban average was reached in the post-project period (Fig. 2a, b). The project, its work and achievements are documented in a number of evaluation reports available online (Pyle and Hossain 2004; Sarriot and Jahan 2010). The enduring bridging of the gap with the national averages and elements of ongoing progress on some indicators, albeit at a reduced rate, allowed to conclude for a reasonable measure of sustainability of the efforts prior to 2004 .

\footnotetext{
1 Some indicators had caught up with and overtaken the secular trend for urban health in Bangladesh, as measured by National Bangladesh Demographic and Health Surveys' urban estimates.
} 

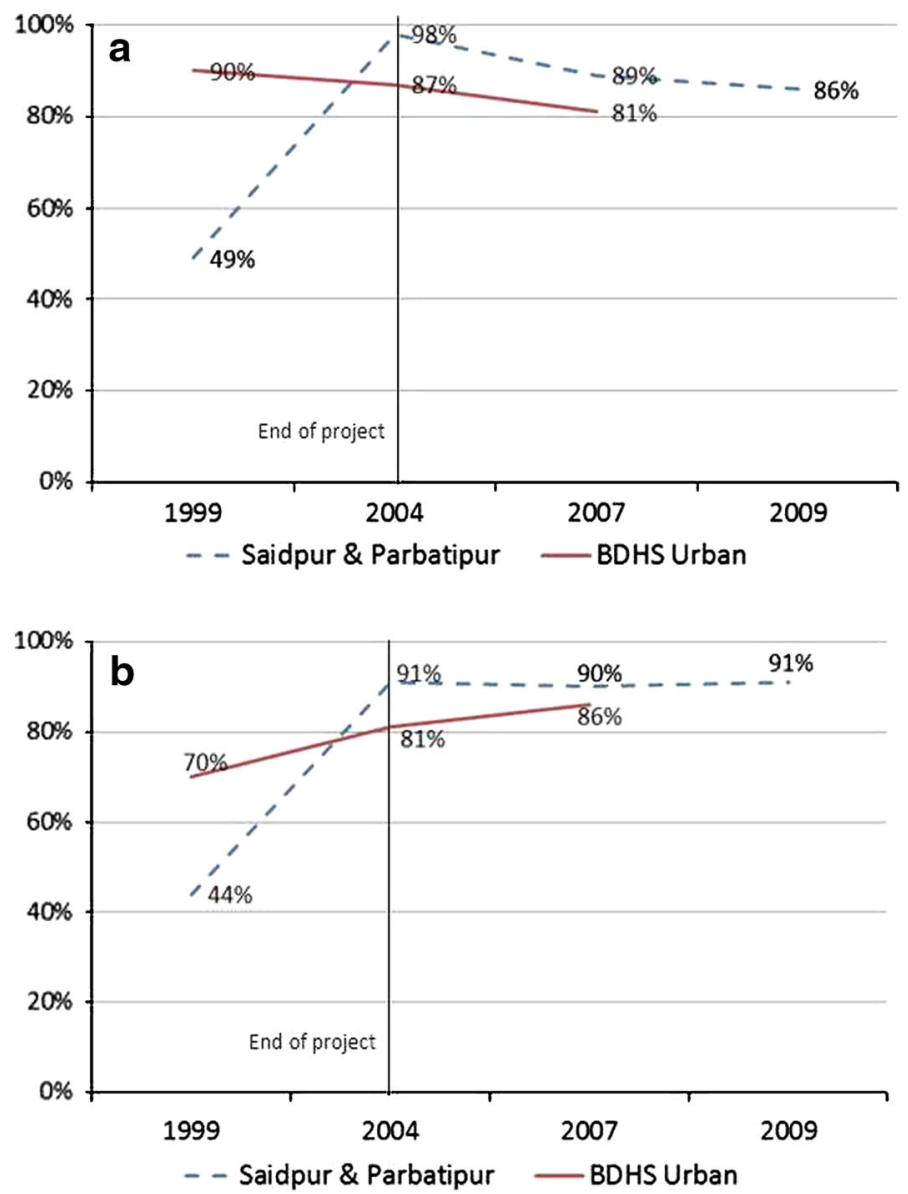

Fig. 2 Comparison between two Saidpur and Parbatipur health indicators over time with national urban estimates: a Percentage of women who received at least two doses of tetanus toxoid during their last pregnancy; b Percentation of children under two fully immunized

Our aim is only to extract specific lessons and identify how the urban health systems behaved as complex adaptive systems, and how Concern's approach took advantage of this.

\section{Municipal Health Systems as Purposive Complex Adaptive Systems}

Multiple, Diverse Actors, with Adaptive Strategies

Concern was not interested in systems theory, but it realized that multiple stakeholders would affect long-term health on different levels in the municipalities: Ministry of Local Governance and Rural Development (MOLGRD), Ministry of Health (MOH) district level, community leaders, municipality workers, elected officials, volunteers or aspiring volunteers, and, of course, municipal residents. Figure 3 illustrates the diversity and multiplicity 
of stakeholders or agents ${ }^{* 2}$ of a local system nested within larger systems, such as national government and districts. This map, drawn during a sustainability assessment, represents the municipal health system structures involved in determining the sustainability of progress in health indicators achieved during the life of the project. The MHD itself fits within a much broader and complex network of actors and institutions.

Agents within this local system clearly adapted to each other based on individual institutional strategies. Municipalities tried to adapt to the set of rules established by the Ministry of Local Government and Rural Development, and they adapted to the presence of Concern itself. Volunteers adapted by first attempting to create an organization and then letting that organization vanish or become subsumed in the Ward Health Committees (WHCs) to ensure that the municipal health department staff would be hired from their midst, a negotiation or cooptation process depending on perspective. The District Health Office (DHO), which normally met with the municipality through the Municipal Health and Social Sector Coordinating Committee, used the changes observed in the municipalities to collaborate and achieve remarkable outcomes in immunization coverage, one of its main priorities (Fig. 2a, b).

Traditional project evaluation is highly concerned with the question of attribution of results. Both project and post-project evaluations attributed the achievements to a successful multi-partner or networked collaboration (Pyle and Hossain 2004; Sarriot and Jahan 2010).

\section{Change in Capacity and Progress Toward Sustainability Were Not Linear}

The progress that was achieved from 1999 to 2009 illustrated in Fig. 2a and b certainly was not linear. Let us, for example, consider Concern's approach to capacity building.

Concern conducted assessments of WHCs and municipalities in order to guide capacity building. It expected capacity building to lead to the development of the required capabilities and ultimately to the performance of the WHCs. The process of capacity building however took on a much less discrete form. It took some time to validate capacity assessment tools, while municipal staff began implementing activities and project staff provided ongoing coaching and support. Joint efforts to validate the capacity assessment tools actually helped define normative institutional behaviors. Consequently, the assessment of capacity served a capacity building role in and by itself.

Another example of non-linearity is sustainability itself (the ability to sustain health outcomes). (Geyer and Rihani 2010; Geyer 2011) present change as a complexity cascade. We use this model in Fig. 4 to illustrate the progress of Saidpur and Parbatipur toward sustainable child health from 1999 until 2009. Time is on the vertical axis and performance of the system (i.e., child health status) is on the horizontal axis. At each stage of assessment, the range of opportunities open to the municipal health system is wider or narrower based on evolutions from the previous phase. Concern directly influenced the path from (a) to (c). (The project served as a gateway event*, disturbing the prior status quo or equilibrium*). By 2009, the priorities of local actors and emerging opportunities, provided sufficient attractors* for their collective behavior to maintain, albeit imperfectly, the newfound equilibrium, with both advances and slippage on specific indicators ( $\mathrm{d}$ and e).

${ }^{2}$ Uncommon terms described in Appendix 1 are signaled with a $*$ symbol. 


\section{S\&P Urban Health System, Bangladesh}

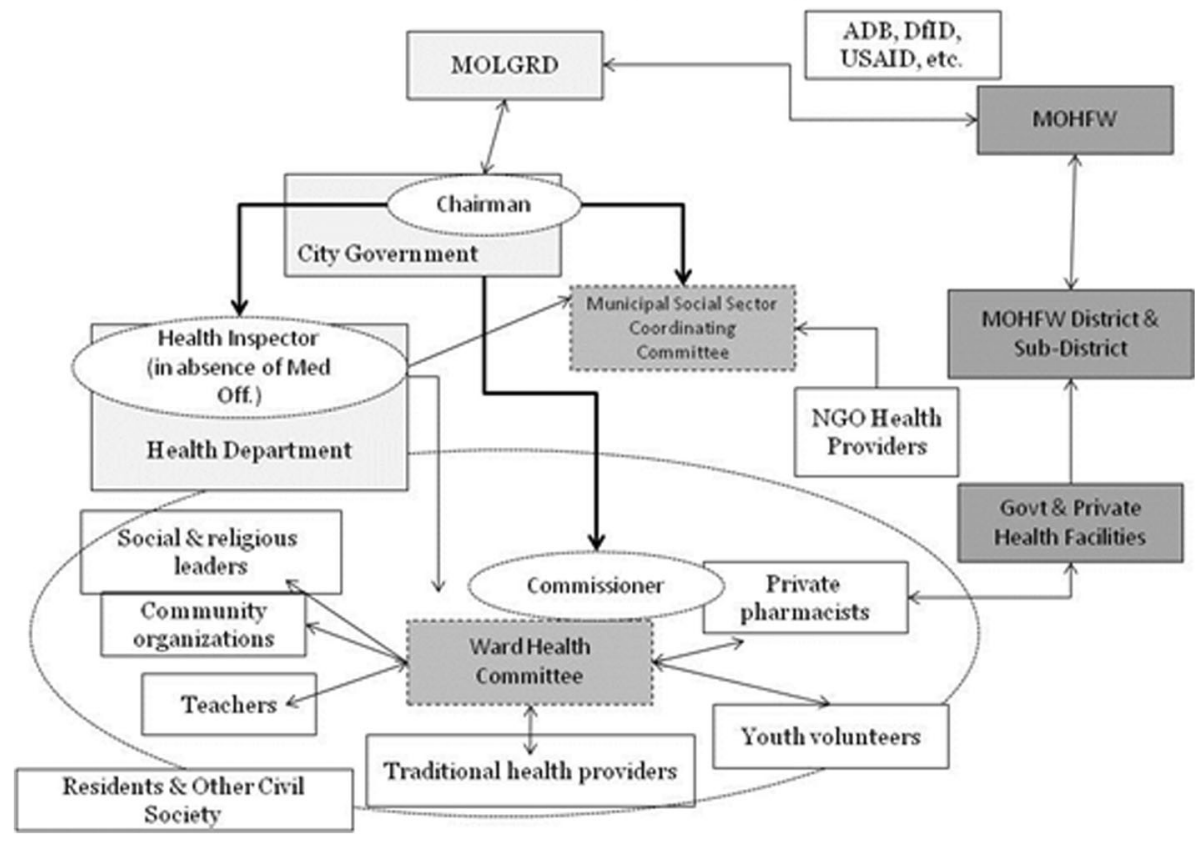

Fig. 3 The Saidpur and Parbatipur Municipal Health System-an open complex adaptive system

Additional Complex Adaptive System Behaviors

We identify two additional behaviors, which fit those of CASs. Paina and Peters (2011) discuss among others the importance of 'prior conditions' as CAS properties which are observable in health systems. After the end of project, the newly achieved health status of children became one important determinant of its future maintenance (as illustrated in Fig. 2a and b in the 2004-2009 period), illustrating the importance of prior conditions. ${ }^{3}$ Finally, Fig. 4 shows that unpredictability endures, with at least two scenarios (f1 and f2) for the post-2009 period.

The Praxis Perspective: How Concern Intervened in the Health System of the Two Municipalities

\section{Constructing a Vision and Spreading Valued Criteria}

Different authors offer recommendations about advancing social change through the unpredictability of complex social systems. Page (Miller and Page 2007) emphasizes the value of diversity in agents' in identifying solutions that combine expertise and perspective. Another recommendation is the use of 'social activity to support the growth and spread of valued criteria' (Axelrod and Cohen 2001). We consider now, how Concern brought these concepts into operation.

\footnotetext{
${ }^{3}$ Paina and Peters also discuss 'path dependence', which is also illustrated by the complexity cascade.
} 


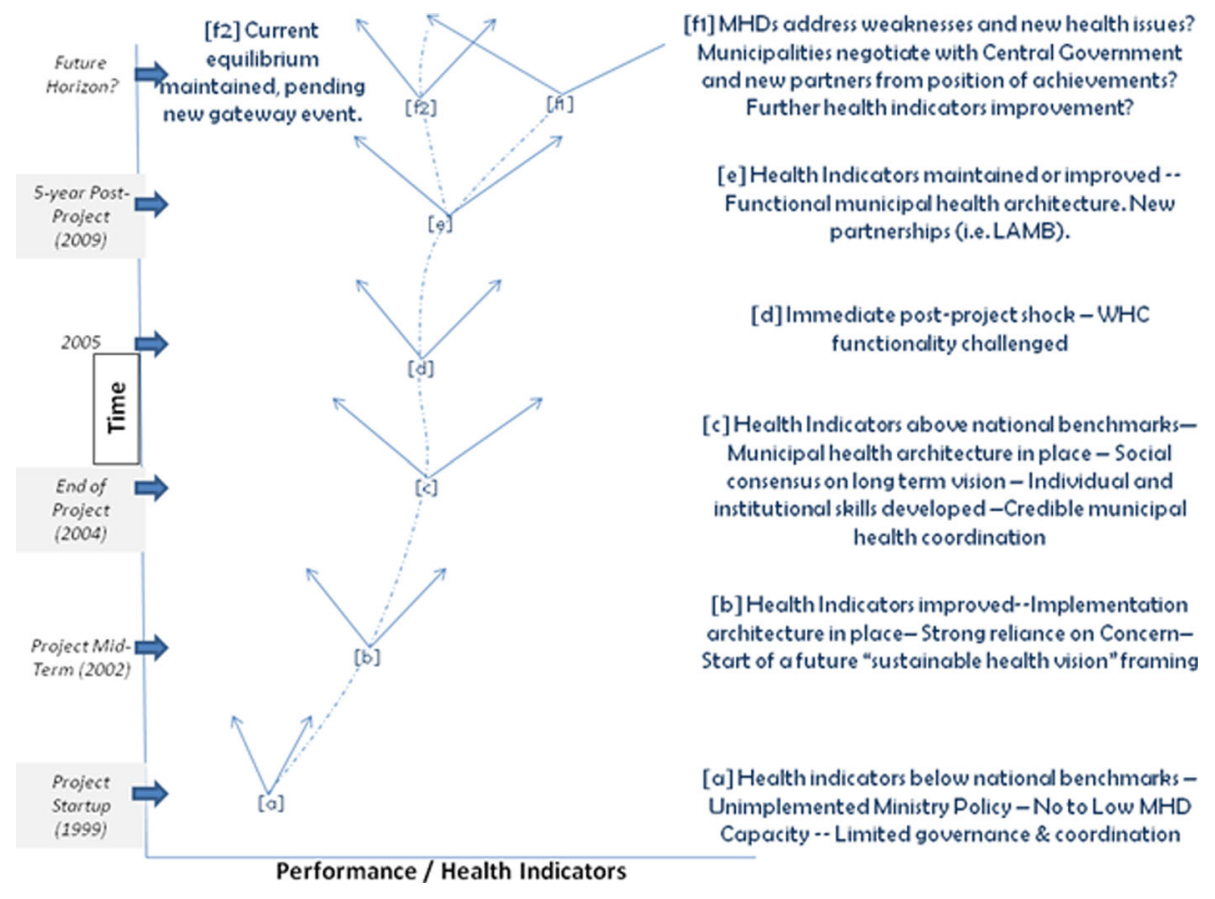

Fig. 4 A complexity cascade for municipal progress toward sustainable health outcomes (adapted from Geyer and Rihani)

Concern first used the early steps of the sustainability framework to map out and define a shared vision. Figure 5 presents a snapshot of a large scale participatory graphic representation of the stakeholders' vision for sustainable child health. Concern's work culture, as a number of non-governmental organizations, relies heavily on participatory methodologies derived from action research and participatory learning and action. Adaptation of these methods to sustainability planning was a natural fit. Similarities with "rich pictures" from other sectors of systemic practice are obvious. The collective, intangible "vision" constructed by local system stakeholders is probably not so much the formal written statement that was developed with the support of Concern, but equally the visual exercises and diagrams, the critical discussions they allowed, and ultimately the constancy of purpose with which the project brought back stakeholders to consider progress made at different stages.

The project brought together different stakeholders to review evidence at project midterm, to consider the future of health promotion and health outcomes beyond the life of the project and the end of project, 1 year later when WHCs were visited (d in Fig. 4), to review the findings of the population health survey 3 years after end-of-project, and to participate in the first sustainability assessment (2007). While it is difficult to tease out the effect of any single review step, the overarching practice of iterative steps between hard data, analysis, sense-making and decision making led to favorable management decisions by the municipalities (from the perspective of sustainability) both during and after the project ended. 


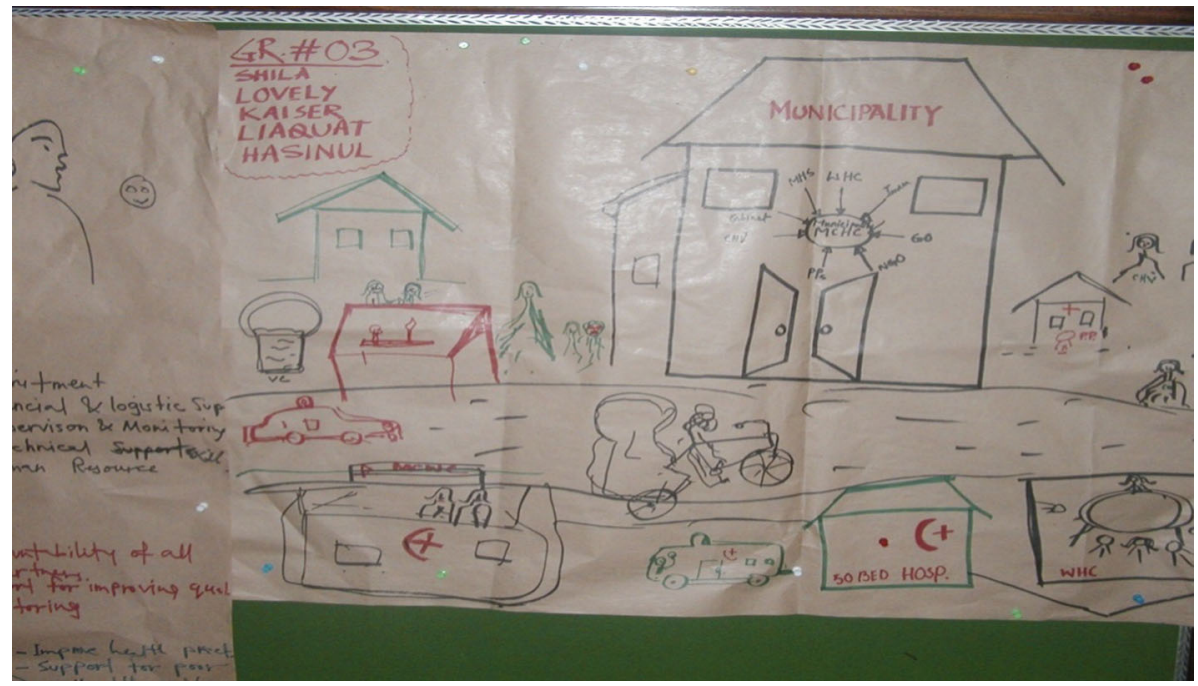

Fig. 5 Section of a pictorial vision for Sustainable child health created by Concern Bangladesh and local municipality stakeholders

The commonality of vision between stakeholders might have been less important in the long-term than the fact that each stakeholder's discrete strategy-the echo of perhaps implicit individual visions - could be compatible with the others'. In fact, each stakeholder probably had a different perspective about the long-term goals (common vision for sustainable health): For example, community women likely saw the benefits in very direct terms, while the collective pursuit of a socially reinforced goal created for WHC members (elected community members) access to the WHC Chair, an elected official, in addition to social recognition from the community.

Population health indicators such as immunization rate, skilled attendants at deliveries, exclusive breastfeeding - elements of information rarely available at this level of a health system-provided low cost but reasonably reliable (Davis et al. 2009) signals to technical staff from the health district, the municipal health teams, and even volunteers. Reporting on evidence of progress on meaningful indicators also built the value of the municipal health activities for these professional and volunteer personnel.

For the WHC Chairpersons and the mayors, measures of change provided an opportunity to be seen as benefactors and leaders of the community. During our final debrief in 2009 , when some of the shortcomings of the municipal health systems were described with a relative flattening of health indicators' trends, the first mayor suggested thoughtfully that an indicator could be improved from 50 to $70 \%$ in the near future. At this point, the second mayor jumped from his chair, proclaimed that this was not enough and that his municipality would certainly reach $200 \%$ in no time! Participants smiled and politely laughed at the hyperbole. This however illustrates how political posturing can have its own agenda, but nonetheless contribute to 'growth and spread of a valued criterion' (Axelrod and Cohen 2001).

Concern acted based on development principles, not explicitly a systems theory, but its approach built on central elements of systems thinking (Williams and Hummelbrunner 2010): definition of the municipal health system boundaries, combining perspectives from 
multiple stakeholders to develop a joint vision and sustainability scenario, providing information feedback to technical and political actors, analyzing sub-systems (i.e. WHCs) nested within the larger municipal health system and analyzing relationships and interdependency among actors. In so doing, the project opted for a learning approach that is essential to the viability of the system.

\section{Building Networks of Trust and Cooperation}

Having focused multiple stakeholders with different strategies toward some recognized and shared value, Concern also supported the development of citizen-municipality networks: the Ward Health Committees (WHCs). WHCs had started de novo with Concern, but under the auspices of a national policy. Five years after the end of external investments, their existence and attributes (funds, bank account, positions, and membership) remained valued and respected by the community and its elected officials. They provided a platform for citizen engagement with the Chairpersons from their area. The participatory and relational aspect of the project's implementation can be seen as building 'networks of relationships and trust and cooperation', another key ingredient recommended by Axelrod (Axelrod and Cohen 2001).

The strengthening of relationship networks took place through the stakeholder gatherings already mentioned, through project officers' visits to municipal staff and WHCs, and the institutionalization of various consultative meetings, which continued without the project (WHC meetings, municipal health department meetings, and coordination committee, etc.). The consistency of Concern's involvement with stakeholders, and the credibility built by Concern due to genuine participatory instincts cannot be overestimated. Ultimately the network of relationships expanded beyond Concern's involvement, when the LAMB hospital $^{4}$ —a local non-profit—adapted its strategy and started to work more intentionally with municipalities after the end of Concern's project, based on the new capabilities and demonstrated motivation of the municipal health departments (step e in Fig. 4).

\section{Adaptive Responses and More Nonlinear Effects}

The 2007 and 2009 post-project assessments documented two important elements for achieving a measure of sustainability in health improvements. In both cases, no pre-defined program plan could have accounted for these adjustments:

- Project activities stopped in 2004. By 2005, Concern, which had moved to neighboring towns, observed that WHC activities had stopped. Concern was then able to allocate just one staff, for 1 day a week in each of the municipalities to focus on coaching and monitoring until 2007. This small adaptive response worked. At the time of the 2009 assessment, the WHCs were still functional; they had members, as well as chairmen and chairwomen; had bank accounts with monies; and carried out some activities (not all expected activities, however). The simple encouraging presence of just one staff at a critical time turned around the prospects for WHCs.

- The municipalities and the Ministry of Health perceived the absence of medical officers $^{5}$ as a weakness of the municipal health system. This absence was due to

\footnotetext{
4 The Lutheran Aid to Medicine in Bangladesh hospital has been in Parbatipur since Independence.

5 The Ministry of Local Government's policy prescribes that Municipal Health Departments should be led by a Medical Officer.
} 
Table 1 No free lunch in community health

No centrally or globally planned solution can be devised to optimally solve a problem in all contexts (or anticipate all opportunities).

Local capacity to adapt to globally unpredictable problems is essential to sustaining social and health outcomes.

constraints in the national human resources for health context. The two health inspectors, however, normally slated to support medical officers, saw this as an opportunity to increase their clout and adapted reasonably well to the absence. In one case, this provided extra motivation for the health inspector, who came to be seen by most as a major catalyst for the results of that municipality.

These observations echo analyses of complexity researchers from different sectors, who have concluded and demonstrated that there is no panacea (Ostrom et al. 2007) and no 'free lunch' (Wolpert and Macready 1995) in solutions to complex problems. In other words, no solution can be devised to optimally solve a problem in all contexts. Local capacity to adapt to globally unpredictable problems is thus essential to sustainability. No centrally or globally planned solution can anticipate all emerging challenges or opportunities (Table 1).

\section{Discussion}

\section{Understanding and Accepting the Complexity of Community Health Systems}

The example of Saidpur and Parbatipur shows us that we need to get better at identifying the complexity of the situation, and our intervention, before trying to scale up simple solutions. Figure 6 presents a complexity matrix (Geyer and Rihani 2010), adapted to some global health questions. It presents an increasing level of complexity along a continuum from right to left, as the number of agents, agent types and connections between them increase. As the number and diversity of agents involved in sustaining a set of goods and services increases, the complexity of the system being affected and, consequently, the complexity of intervention effects (intended and unintended) increases. Some issues will respond to linear (orderly) strategies, while others are part of complex interactions and will not be effectively managed through linear approaches. At some point, excessively linear models will be self-defeating by constraining the adaptive capacity of the system (Rihani 2002a). Sustaining the quality of immunization services in a single clinic will certainly involve complex elements, but not to the same extent as sustaining child nutrition within rural households. Financially sustaining a network of service providers will also involve complexity, but not to the same extent as sustaining positive health outcomes in poor communities nationally through the coordinated efforts of public and private agents.

This basic understanding is now spreading across various types of agencies, from donors to researchers. In the middle, practitioners sometimes feel vindicated for their advocacy for the necessity of 'participation', 'empowerment', and 'holistic approaches', but are also are somewhat skeptical about what they perceive as just a new branding of the same old concepts. There is also some apprehension for 'systems approaches', because of a perceived focus on large system components (infrastructure, policies, financial flows, human resources, information systems, etc.) that does not pay adequate attention paid to the end point of services to and outcomes for beneficiaries. This macro-micro tensions, 
MORE DISORDER

More agents, agent types, and interactions

\begin{tabular}{|c|}
\hline Sustaining \\
population \\
health through \\
Bangladeshi \\
political and \\
institutional \\
changes \\
\hline
\end{tabular}

\begin{tabular}{|l|}
\hline Developing and \\
managing new \\
municipal \\
partnerships \\
focused on \\
accepted public \\
good
\end{tabular}

\begin{tabular}{|l|}
\hline Adaptive health \\
system \\
management \\
based on \\
evidence and \\
reliable flow of \\
information \\
\hline
\end{tabular}
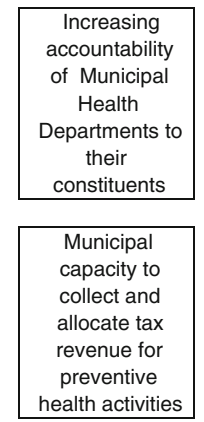

District-

Municipal

autonomy in

producing and

utilizing health

information
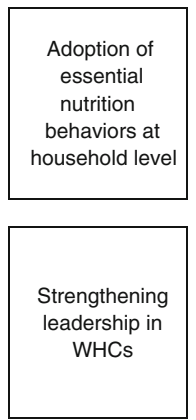

Health staff

data use to

improve

services and

coverage

MORE ORDER

Fewer 'agents', agent types, and interactions

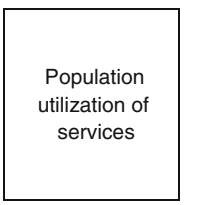

Proper and safe administration of

immunizations

in facilities by

care providers
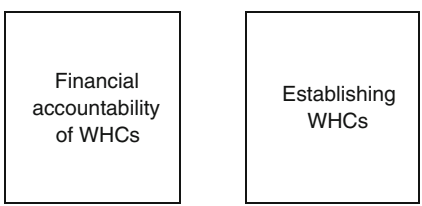

Building health staff capacity in reporting routine health data

Producing

population-

based health

information

Fig. 6 Illustrative complexity matrix for sustainability of different global health objectives

perceived or real, is a false representation of what complexity science and systems thinking can teach global health professionals. What we see from the example of Saidpur and Parbatipur is that there is a constant interplay between micro and macro factors. (Morin 2005) A complex systems approach to community health is thus not about being macro rather than micro, but about finding tools to appropriately address this interplay.

Entering a Complex System: Implications for Health and Development Projects

Resourced health and development projects usually have specified, rigid timeframes and high expectations for change. These projects create two shocks to a local system: one, when they enter and another when they leave. In both cases, local systems need time to adapt to a new reality. In such circumstances, considering time as a mere constraint is risky, and an even greater risk comes from considering financial resources as a matching solution. It is far sounder to consider time as a fundamental factor of system adaptation.

Both biological and social systems need time for regularities* to be expressed (Rihani 2002b). In the Concern example, the project benefited from the opportunities that USAID and private donors provided: a fairly long entry phase for baseline assessments and detailed plans $^{6}$; the ability to redesign, based on a mid-term evaluation; the possibility to make a small reinvestment in the two municipalities after the end of project in 2005; and repeat involvement through the sustainability assessments in 2007 and 2009.

Saidpur and Parbatipur, as other places (Sarriot et al. 2010) required time to achieve results, and as actors of the system learned and adapted. Partners such as the LAMB

\footnotetext{
${ }^{6}$ Under the U.S. Agency for International Development's Child Survival and Health Grants Program rules, Concern had nine months to carry out baseline assessments and engage stakeholders in participatory planning activities.
} 
hospital learned to trust the value of the Municipal Social Sector Coordinating Committee, not just because it was effective but also because it had been effective for a few years. A major predictor of WHCs' capacity to maintain their infrastructure by 2009 started with the basic capacity established early on and built on the actual length of time they had remained in function, including through election cycles. In fact, the existence of WHCs had become a new norm for municipalities over time.

The nature and purpose of change is socially constructed, and unwanted effects are, in essence, regularities in large organizational change (Jian 2007). In multi-institutional systems, the time-resource-ownership inadequacy, if left uncorrected, offers fertile ground for unwanted effects. For example, the most predictable unwanted effect of large projects in poor settings is increased competition for resources, especially if the local environment perceives the project as picking winners. It is natural for agents' strategies to organize around this competition, rather than around cooperation for an uncertain public good. We may blame bad leadership, bad governance, even culture (Harrison and Huntington 2000), and try to change human nature through transformative change, but it may be wiser to consider more explicitly how human behavior finds attractors in the social context where it takes place.

Thus, one main challenge for projects is to work on discrete and technical sub-system changes, while also allowing the emergence of system-wide adaptive behaviors. The scale and context of this challenge may be unique, but its nature is not (Table 2).

Concern's use of the sustainability framework increased critical dialog and contact between municipal system agents, identified subsystems issues, framed a vision, provided information or helped agents of the system produce information they could make sense of, and focused efforts of a diversity of agents (political, technical, and social) on fundamental questions about the future of child health in their community. The loaded terms of 'participation' and 'empowerment' simply may be part of intentionally respecting the complex adaptive nature of community health. This does not mean that involving stakeholders has magical properties. More accurately, the challenge may be to use social networks and shared learning to develop a societal framework as stated below:

[...] as seen in physical and biotic complex systems, too much diversity can lead to negative outcomes as well. If each individual pursues completely autonomous actions, advanced human relations would quickly break down. ....

... if common human experiences were not interpreted [...], how could one create a collective understanding? How would others learn from and adapt to that shared experience? Here, if you will, lies the relativist nightmare. Human capacities enable us to obtain an enormous amount of diverse actions and interpretations. However, without some level of commonality or boundaries, complex human interaction experiences a complexity catastrophe and the gains of human consciousness are lost. Without some form of evolving societal framework, human actions and interpretations begin to resemble random noise and do not allow for the creation of emergent stable pattern (Geyer and Rihani 2010).

\section{Combining Strategy with Allowance for Self-organization and Emergence}

We only scratched the surface of the question of complexity in community health, but hopefully addressed some salient questions. We document in the example of Concern's programmatic instincts, strategy and practice how local agents can come together to guide change and allowing a measure of sustainability in a complex local adaptive system. The 
Table 2 Complex systems lessons from other sectors

Other sectors can help us understand the limits to what we can intentionally design, and accept that complex
adaptive systems will continue finding their own equilibriums even if some of their actors choose to
cooperate with us for a while. Jackson (2006) provides a solid conceptual, methodological, and historical
description of increasingly holistic approaches to organizational management. His System of Systems
Methods describes management approaches, which address increasing levels of complexity in
management systems. Patton (1990) also discusses the continual construction of goals, purposes, roles and
relationships within complex adaptive systems, and how this affects evaluation practice. The field of
sustainable development has long preceded us in trying to influence, rather than coerce adaptation
(Meadows 1998), and complexity scientists are describing sustainability as an emerging property of
Human-Environment Systems (Tian 2008).

development of relationships of trust and cooperation, and the use of negotiation and information helped focus multiple agents* on the public good and shared values.

Many failed attempts at sustainable change in massive projects can be linked to an imbalance between a reliance on the project as a gateway event* and a consideration of the time required for learning and for social engagement. Addressing more complex problems (i.e., sustainability rather than results, ownership rather than compliance, adaptive capacity rather than technical skills) will require us to develop new tools, new guidance for entering and leaving local systems.

Considering the shock to the system of project interventions, a substantial element of the sustainability equation is how to build the required societal framework at each level of intervention-possibly the heart of the ownership question. Unfortunately, projects can be blind to entropy and unwanted effects. They can be tempted to brush the likelihood of unintended effects under the rug, because projects are themselves managed by humans who have to adapt to donors and local governments as part of their own professional and personal strategy. For donors and central government alike, the greatest challenge then becomes trying to create an outcome that is not entirely controllable (Sarriot 2009), through learning and adaptation, creating opportunities for larger and more lasting progress, even at the risk of 'small failures' (Axelrod and Cohen 2001). ${ }^{7}$

Planners, implementers and donors have a natural and justifiable tendency to want to control outcomes. Who wants to write a proposal that does not guarantee success and sustainability? Who wants to write the call for proposals that asks the grantees to avoid 'sowing large failures when reaping small efficiencies' (Axelrod and Cohen 2001)? Systems thinking, practice, and evaluation consequently challenge the architecture of development projects. The emphasis on scale of the past years is welcome if it means scaling benefits to poor and marginalized communities; however, if scalability is designed against contextually adaptive responses and solutions and ignores time-sensitive change processes built on new attractors for local agents imbued with free will, or if it assumes a belief in global panaceas, which local complexity will doom to failure, then our good intentions risk meeting severe disappointments.

We can, nonetheless, achieve better, more sustainable results by learning to embrace the complex nature of the world that we want to affect. If we lose some of the comfort and pretense of predictability by more effectively combining linear models, as possible, with complex models when required, we may find some solace from an old tune: 'You can't

\footnotetext{
7 In complex systems theory, this refers to the balance between exploitation and exploration (Miller \& Page, 2007). It also relates to Morin's (Morin, 2005) and others' (Rihani, 2002b) discussion of the necessity of cycles of destruction-construction in adaptive systems. Examples abound, starting with the human body, democracy, or the market.
} 
always get what you want. But if you try sometimes, you just might find you get what you need' (The Rolling Stones 1968).

Acknowledgments This work references the Concern Worldwide Inc. Child Survival Project in Saidpur and Parbatipur, which was supported by the US Agency for International Development under the cooperative agreement FAO-A-00-00-00039-00. The views expressed here are those of the author, not of USAID, Concern Worldwide Inc., or ICF International.Particular thanks for critical inputs and significant contributions to go to Michelle Kouletio, Shamim Jahan, and Izaz Rasul. This paper is much indebted to the platform built by your earlier essential intellectual contribution. I am grateful to the following colleagues, members of the Saidpur and Parbatipur Sustainability Evaluation Team for their substantive contribution to the original evaluation exercises which have led to this publication: Amirul Islam, Zamal Uddin, Lovely Yesmin, Shakila Banu, Abdur Rahim, Afsana Khatun, Abed Hossain (Hera) Khan, Rafiquzzaman Babu, TM Prince Nobi, Megan Christensen, and Moire O' Sullivan. Credit goes to the authorities, professionals and volunteers of Saidpur and Parbatipur, and to all the Concern staff who were involved throughout the years. Thank you to Reeti Desai, Lynne Jennrich, and Natasha Wad for your assistance.This paper is dedicated to the late Mr. Mofiz, Health Inspector of Parbatipur, a human being of heart and dedication and a skilled public health professional.

Conflict of interest Eric Sarriot carried out the 3 years post-project sustainability evaluation of the Saidpur and Parbatipur Project under a consulting agreement with Concern Worldwide Inc., and carried out the 5 years post-project sustainability evaluation through a contract between Concern and ICF International, his current employer. Eric Sarriot declares no involvements that might raise the question of bias in the work reported or in the conclusions, implications, or opinion stated. Michelle Kouletio previously worked for Concern and declares no involvements that might raise the question of bias in the work reported or in the conclusions, implications, or opinion stated.

Open Access This article is distributed under the terms of the Creative Commons Attribution License which permits any use, distribution, and reproduction in any medium, provided the original author(s) and the source are credited.

\section{Appendix 1: Clarifying our Language: Systems or Complexity or Both?}

A substantial body of work discussing systems theory and complexity appears in both physical and social sciences (Axelrod and Cohen 2001; Geyer and Rihani 2010; Heng 2008; Jackson 2003, 2006; Miller and Page 2007). We rely on it to clarify our language:

A system is 'a regularly interacting or interdependent group of items forming a unified whole'. ${ }^{8}$ System theory and systems thinking refer to a range of holistic methods attempting to consider cause and effects within a whole set of conditions in components constituting a system (Jackson 2006). Systems exist in almost all fields of scientific inquiry, and present themselves with varying degrees of complexity.

Complexity itself is a field of enquiry about phenomena, which occur within systems between order and chaos (Miller and Page 2007). Definitions abound without a single consolidated one. Geyer and Rihani (2010) identify more than 30 definitions in current use, and there are probably more. In general, complexity involves multiple relationships, processes subject to amplifying or regulating feedback loops, non-linear cause and effect relations notably when dealing with problems of aggregation (from the micro to the macro level) (Mitchell 2011). Toward the chaos end of the spectrum, complex systems display sensitive dependence on initial conditions, which lead to unpredictability.

Confusion in language comes from different directions. First, as summarized by Richardson et al., "the terms "systems" and "complexity" have been very closely

\footnotetext{
${ }^{8}$ Merriam-Webster, 2012.
} 
associated', with organized complexity essentially referring to systems, and applied systems thinking being an approach to help us deal with complexity.(Richardson and Cilliers 2001, Richardson 2007) (Phelan 2001) frames this as a distinction between complexity science and complexity theory. He describes complexity science as an attempt to find predictive rule for regularities, in other words, a reductionist effort to find 'simple causes to complex effects', generally through mathematical and computer models (Phelan 2001). Whether or not this can evolve toward a single universal theory of complexity is an enduring debate. On the other hand, complexity theory is a more applied understanding of complexity for the purpose of understanding systems, managing and designing interventions, recognizing that in open systems, multiple agents and sub-systems interact with one another and their environment according to multiform patterns.

Moving closer to the area of our interest, complex adaptive systems (CAS) are described in biology, ecology, and, over time, with organizations, societies, political groups, institutional systems, etc. The term complex adaptive system is generally associated with GellMann and colleagues at the Santa Fe Institute (Jackson 2006; Miller and Page 2007). A number of definitions for complex adaptive systems exist, and their characteristics vary depending on the authors and their specialty. Miller and Page (2007) offers a reasonably simple way of defining a CAS:

1. As all systems, CAS are open systems, with rich internal interactions and links to a larger external environment;

2. A large number of agents are in a system;

3. These agents vary in type; and.

4. These agents adapt to each other on a constant basis.

Social, political, and organizational systems have the particularity of being purposeful complex adaptive systems, which means that agents are endowed with some level of free will to define their own individual strategies within a system, based on information received about other agents' behaviors.

While agents follow individual seemingly idiosyncratic and unpredictable strategies, these can lead to the expression of a system level recognizable and stable phenomenon. This is the essence of emergence. Along the way, regularities are predictable patterns of system or sub-system organization created by emergent system behaviors or the aggregation of individual agent behaviors, which might themselves be unpredictable.

\section{References}

Axelrod R, Cohen MD (2001) Harnessing complexity: organizational implications of a scientific frontier. Simon and Schuster, New York

Baser H, Morgan P (2008) Capacity, change, and performance: study report (Rep. No. 59B). European Centre for Development Policy Management, Maastricht

Bossel H (1999) Indicators for sustainable development: theory, method, applications. A report to the Balaton Group. International Institute for Sustainable Development, Winnipeg

Brinkerhoff DW, Morgan P (2010) Capacity and capacity development: coping with complexity. Public Adm Dev 30(1):2-10

Davis R, Luna J, Rodriguez-Lainz A, Sarriot E (2009) The rapid household survey: how to obtain reliable data on health at the local level. ICF Macro, Calverton MD, Public Health Institute, Oakland CA

de Savigny D, Adam T (2009) Systems thinking for health systems strengthening. Alliance for Health Policy and Systems Research, World Health Organization, Geneva 
Easterly W (2006) The White Man's Burden: why the West's efforts to aid the rest Have done so much ill and so little good. Oxford University Press, Oxford

Gasparatos A, El-Haram M, Horner M (2007) The argument against a reductionist approach for assessing sustainability. In: Horner M, Hardcastle C, Price A, Bebbington J (eds) International conference on whole life urban sustainability and its assessment. Glasgow

Geyer R (2011) Can complexity move UK policy beyond 'evidence-based policy making' and the "audit culture"? applying a 'complexity cascade' to education and health policy. Polit Stud 60(1):20-43

Geyer R, Rihani S (2010) Complexity and public policy: a new approach to 21 st century politics. Policy and Society, Routledge

Gruen RL, Elliott JH, Nolan ML, Lawton PD, Parkhill A, McLaren CJ, Lavis JN (2008) Sustainability science: an integrated approach for health-programme planning. The Lancet 372:1579-1589

Hafner T, Shiffman J (2013) The emergence of global attention to health systems strengthening. Health Policy Plan 28:41-50

Harrison LE, Huntington SP (2000) Culture matters: how values shape human progress. Basic Books, New York

Heng H (2008) The conflict between complex systems and reductionism. JAMA 300(13):1580-1581

Hodgins S (2014) Achieving better maternal and newborn outcomes: coherent strategy and pragmatic, tailored implementation. Glob Health Sci Pract Advance Access. doi:10.9745/GHSP-D-13-00030

Jackson M (2003) Systems thinking: creative holism for managers. John Wiley \& Sons, Chichester

Jackson MC (2006) Creative holism: a critical systems approach to complex problem situations. Syst Res Behav Sci 23(5):647-657

Janovsky K, Peters D (2006). http://www.who.int/management/Making\%20HSWork\%205.pdfImproving Health Services and Strengthening Health Systems: Adopting and Implementing Innovative Strategies (Rep. No. Working Paper No. 5). Department of Health Policy, Development and Services, WHO

Jian G (2007) Unpacking unintended consequences in planned organizational change: a process model. Manag Commun Q 21:5-28

Lafond AK (1995) Improving the quality of investment in health: lessons on sustainability. Health Policy Plan 10:63-76

Meadows D (1998) Indicators and information systems for sustainable development. A report to the Balaton Group. The Sustainable Institute, Hartland Four Courners

Miller JH, Page SE (2007) Complex adaptive systems: an introduction to computational models of social life. Princeton University Press, Princeton

Mitchell M (2011) Complexity: a guided tour. Oxford University Press, Oxford

Morin E (2005) Introduction à la pensée complexe. Éditions du Seuil

Ostrom E, Janssen MA, Anderies JM (2007) Going beyond panaceas. Proc Natl Acad Sci USA 104:15176-15178

Paina L, Peters DH (2011) Understanding pathways for scaling up health services through the lens of complex adaptive systems. Health Policy Plan 26:1-9

Patton MQ (1990) Qualitative evaluation and research methods, 2nd edn. Sage Publications Inc, Newbury Park

Peters D, Paina L, Bennett S (2012) Expecting the unexpected: applying the Develop-Distort Dilemma to maximize positive market impacts in health. Health Policy Plan 27:iv44-iv53

Phelan SE (2001) What is complexity science, really? Emergence 3:120-136

Pyle D and Hossain J (2004) USAID-Municipality_Concern Worldwide Bangladesh Child Survival Partnership Program. Final Evaluation Report. Saidpur and Parbatipur Municipalities, Rajshahi Division, Bangladesh. 1 Oct 2000-30 Sept 2004 Washington, DC: Cooperative Agreement No. FAOA-00-98-00077-00

Ramalingam B (2013) Aid on the edge of chaos. Rethinking international cooperation in a complex world. University Press, Oxford

Ramalingam B, Jones H, Reba T, Young J (2008) Exploring the science of complexity: ideas and implications for development and humanitarian efforts, 2nd edn. Overseas Development Institute, London

Richardson KA, Cilliers P (2001) Special editors' introduction: What is complexity science? a view from different directions. Emergence 3(1):5-23

Richardson KA, Gregory JW, Midgley G (2007) Editorial introduction to the special double issue on complexity thinking and systems theory. Emergence 9:1-2(vi-viii)

Rihani S (2002a) Complex systems theory and development practice: understanding non-linear realities. Zed Books, London

Rihani S (2002b) Implications of adopting a complexity framework for development. Prog Dev Stud 2:133-143 
Sarriot EG (2009) Black Swans. Grey Swans, Sustainability. CEDARS discussion paper. ICF Macro, Calverton, MD. http://cedarscenter.com/resources.cfm

Sarriot EG, Jahan S (2010) Sustainability of the Saidpur and Parbatipur Urban Health Model (Bangladesh) Five Years After the End of Concern's Child Survival Project. Final Evaluation Report. Concern Worlwide Inc, New York, NY

Sarriot EG, Winch PJ, Ryan LJ, Bowie J, Kouletio M, Swedberg E et al (2004) A methodological approach and framework for sustainability assessment in NGO-implemented primary health care programs. Int J Health Plann Manag 19:23-41

Sarriot EG, Ricca J, Yourkavitch J, Ryan L (2009) Taking the long view: a practical guide to sustainability planning and measurement in community-oriented health programming. Macro International, Calverton, MD

Sarriot EG, Swedberg E, Ricca J (2010) Pro-sustainability choices and child deaths averted: from project experience to investment strategy. Health Policy Plan 1-12

Sarriot EJ, Kouletio M, Jahan S, Rasul I, Musha A (2014) Advancing the application of systems thinking in health: sustainability evaluation as learning and sense-making in a complex urban health system in Northern Bangladesh. Health Research Policy and Systems (in press)

Swanson CR, Cattaneo A, Bradley E et al (2012) Rethinking health systems strengthening:key systems thinking tools and strategies for transformational change. Health Policy Plan 27:54-61

The Rolling Stones (1968) You Can’t Always Get What You Want. [Let It Bleed]. London

Tian Q (2008) Sustainability as an Emergent Property of Human-Environment Systems (CHES). A framework for studying sustainability of CHES. Santa Fe Institute Workshop

Ubels J, Acquaye-Baddoo N, Fowler A (2010) Capacity development in practice. Earthscan, London

Williams B, Hummelbrunner R (2010) Systems concepts in action: a practitioner's toolkit. Stanford University Press, Stanford

Williams B, Imam I (2007) Systems concepts in evaluation. EdgePress of Inverness, Point Reyes

Wolpert DH, Macready WG (1995) No free lunch theorems for search, Technical Report SFI-TR-95-02-010 Santa Fe Institute 